\title{
ESPÉCIES DE DOLO E OUTROS ELEMENTOS SUBJETIVOS DO TIPO
}

JUAREZ TAVARES

Professor de Direito Penal da Universidade Federal do Paraná.

\section{INTRODUÇÃO}

O dolo situa-se, na moderna estrutura finalista do delito, como constitutivo essencial da parte subjetiva do tipo de injusto. ${ }^{(1)}$

Esta sistematização resulta de se entender a ação integrante do tipo em seu momento dinâmico objetivo-subjetivo. A vontade determina-se, é verdade, de modo primário, pelas circunstâncias objetivas (realidade social), mas, por outro lado, a resposta humana (conduta) a uma situação não se determina tão-sòmente pelo lado objetivo momentâneo, senão também pelo seu processo ontogenético de aquisição (passado) e ainda pela função seletiva da atividade refletora da consciência (futuro) no sentido de conservar, alterar ou transformar a condição objetiva. $\left({ }^{2}\right)$ A esta conduta humana, dialèticamente determinada, de relevância social, regida pela vontade dirigida a um determinado resultado, é que chamamos de ação. $\left(^{3}\right)$ O tipo de injusto constitui-se, fundamentalmente, desta ação e, se houver, do resultiado produzido. O dolo seria, em um dizer mais simples, a vontade diretora da ação típica ou, mais em detalhes, a consciência e vontade em relação aos elementos objetivos pertencentes ao tipo. ( $\left.{ }^{4}\right)$ A importância desta configuração decorre da exigência de se corresponderem as partes objetiva e subjetiva do tipo. É possível, entretanto, que, às vezes, em virtude de defeito de congruência decorrente do próprio tipo (tipos originàriamente incongruentes) ou da forma de manifestação concreta do delito, não se verifique esta correspondên-

(1) Veja-se a respeito, particularmente Maurach, Tratado de Derecho Penal, 1962 (tradução espanhola de C. Roda), páginas 301 ss. vol. 1.

(2) Cf. Földvári József, Die determinische Begründung der strafrechtlichen Verantwortlichkeit, 1968 , p. 6 ss.

(3) Veja-se a respeito de um conceito social de ação, Jescheck, Lehrbuch des Strafrechts, A. T. 1969, p. 152 ss.

(4) Cf. Jescheck, Lehrbuch, p. 197. 
cia. No primeiro caso, conforme haja supremacia ou da parte subjetiva ou da parte objetiva, ocorrerão, respectivamente, os chamados delitos de intenção ou tendência (com elementos subjetivos especiais) e os qualificados pelo resultado. Quando os tipos se apresentam originàriamente congruentes, mas se a parte subjetiva ultrapassa a objetiva ou se a parte objetiva ultrapassa a subjetiva, apresentar-se-ão, respectivamente, as situações de tentativa e êrro de típo. $\left(^{5}\right)$

\section{ESPÉCIES DE DOLO}

Partindo desta configuração sistemática do delito, pode-se obter uma melhor focalização do dolo e dos outrora chamados elementos subjetivos do injusto.

As classificações anteriores quanto às espécies de dolo, devem reduzir-se, simplesmente, a duas categorias: dolo direto e dolo eventual. Não há mesmo razão científica alguma na apreciação de terminologias de dolo de ímpeto $\left({ }^{6}\right)$, de dolo alternativo, dolo determinado, dolo indireto, dolo específico ou dolo genético, que podem sòmente trazer confusão à matéria e que se enquadram ou entre os elementos subjetivos do tipo ou nas duas espécies mencionadas. $\left({ }^{7}\right)$

Para uma diferenciação destas duas espécies, é necessário um retrospecto ao conteúdo do dolo. Podemos compreendê-lo como constituído de duas partes: um elemento intelectivo e outro volitivo. O primeiro se refere ao conhecimento de tôdas as circunstâncias objetivas do tipo legal. Nesse momento figuram três situações distintas em relação às circunstâncias do tipo, conforme o autor efetivamente as represente, tome-as em consideração ou apenas tenha pensado nelas, correspondentemente a:

a) elegê-las em objetivo final;

b) tomá-las como meio para um outro objetivo; ou

c) havê-las pensado como circunstâncias acompanhantes ao fato a ser realizado. ${ }^{(8)}$

Estas três posições correspondem, assim, a graus de intensidade da consciência e devem ser tomadas em consideração na determinação da vontade delituosa.

(5) Sôbre congruência e incongruência do tipo, veja-se Maurach, ob. cit. pgs. 273 ss.

(6) O dolo de ímpeto não constitui modalidade especial de dolo. Veja-se inclusive observação nesse sentido de Costa e Silva, Comentários ao Código Penal, reedição 1967, pgs. 89 ss.

(7) A respeito da crítica à terminologia antiga, principalmente Maurach, ob. cit. pgs. 313 .

(8) Cf. Welzel, Das deutsche Strafrecht, 1967, pg. 62. 
O elementos volitivo pressupõe, primeiramente, uma vontade incondicional por parte do agente. $\left({ }^{9}\right)$ A dúvida acêrca do querer ilide a consideração volitiva. Não há, evidentemente, dolo no exemplo da pessoa que, interpelada pela autoridade policial, saca de uma pistola, sem haver decidido se empregará a arma tão-sòmente para ameaçar ou para disparar sôbre seu desafeto. $\left({ }^{10}\right)$ Aqui não se falará de dolo alternativo, que pressupõe vontade certa no sentido das duas alternativas, estando pois o agente disposto, a qualquer prêço, a matar ou a ameaçar, já havendo se decidido por ambos. Além, entretanto, da incondicionalidade, deve o elemento volitivo dirigir-se à realização do tipo. ${ }^{(11)}$ Vontade de realização não significa vontade de ambicionar ou de possuir alguma coisa, mas sim de realizar algo em concreto, que só pode ser tomado por base em relação ao tipo. Esta vontade pressupõe que o autor atribua a si mesmo uma possibilidade de influência concreta sôbre o acontecimento real. ( $\left.{ }^{12}\right)$ Assim, não há dolo, mas apenas desejo ou esperança, no caso citado por Welzel, da pessoa que manda seu adversário a um bosque, em meio a uma tempestade, desejando ou na esperança que seja atingido por um raio $\left({ }^{13}\right)$. Mesmo se tal ocorrer inexistirá vontade de matar, pois esta não pode ser compreendida por uma simples esperança. É o que se dá, nas mesmas proporções, com o caso do sobrinho, que interessado na morte da tia, a instiga a realizar uma viagem em uma estrada de ferro, onde poderá ocorrer um desastre fatal para a sua vida. Neste caso, fala-se, que não chegará a haver até mesmo a própria causalidade, segundo a teoria da causalidade adequada. $\left({ }^{14}\right)$ Mesmo admitindo-se, contudo, o nexo causal, com base na equivalência dos antecedentes, inexistirá o tipo penal, por ausência de dolo. Tudo o que se localiza assim, fora da possibilidade de influência concreta do agente pode ser desejado ou esperado, mas não significa querer realizar. $\left({ }^{15}\right)$ Esta possibilidade de influência concreta, tomada em sentido positivo, é que dá ao aspecto volitivo um caráter realístico, afastando-o das meras especulações abstratas. Entretanto, sendo o dolo um querer realizar compreende nesta sua tarefa as categorias ditadas pelo seu elemento intelectivo. A vontade de realização, portanto, funde-se, numa unidade dialética $\left({ }^{16}\right)$, aos graus de intensidade

(9) Cf. Welzel, Das deutsche Strafrecht, 1967, pg. 63.

(10) Veja-se a respeito a observação de Maurach, ob. cit. pag. 316.

(11) Cf. Welzel, ob. cit. pág. 63.

(12) Cf. Welzel, ob. cit. pág. 63.

(13) Cf. Welzel, ob. cit. pág. 63.

(14) Veja-se Maurach, ob. cit. pág. 237.

(15) Veja-se mais profundamente análise de Welzel, ob. cit. pág. 63.

(16) A respeito de uma tomada de posição dialética do dolo, consulte-se Hellmut-Mayer, Strafrecht, A. T. Studienbuch, pág. 117 ss., 1967. 
da consciência, do que resultam as três posições assumidas com respeito à representação das circunstâncias típicas, com objetivo final, meio para o alcance de outros objetivos ou simplesmente consequências paralelas ou acompanhantes do fato. $\left({ }^{17}\right)$ Estas atuações intelectivo-volitivas originam as duas espécies de dolo conhecidas: dolo direto e dolo eventual, bem como darão os elementos para diferenciar esta ultima espécie da discutida culpa consciente.

\section{DOLO DIRETO}

Diz-se que há dolo direto, quando a vontade de realização associà-se necessàriamente à representação das circunstâncias típicas como objetivo final de sua ação, meio para a consecução de outros objetivos ou como consequências acompanhantes ao fato. Em outras palavras, conforme a precisão de Maurach, atua com dolo direto quem representa como desejáveis ou como necessárias as consequências de seu obrar. $\left.{ }^{18}\right)$. No dolo direto o agente quer o resultado típico ou toma-o como necessário para a consecução de outros propósitos ou como conseqüência necessária de sua atividade.

Referentemente ao objetivo final, elegido pelo autor dentro do tipo, a vontade possui uma direção primária e direta. $O$ agente quer matar e atua neste sentido. O matar constitui seu objetivo. Neste aspecto é indiferente se o alcance do objetivo é tomado como certo ou sòmente como possível, por parre do autor. ${ }^{19}$ ) Assim, quem, encontrando-se a uma determinada distância da vítima, dispara contra esta, com o fim de atingí-la, mas sem possuir a certeza de poder dolo direto. $\left({ }^{20}\right)$ Como bem acrescenta Welzel, sòmente quando o resultado for tido como mero acaso, haverá uma substituição da vontade de realização por uma simples esperança de realização, o que descaracterizaria o dolo. $\left({ }^{21}\right)$

Fala-se ainda de dolo direto de primeiro e segundo grau, segundo Mezger, conforme o autor, respectivamente, deseje diretamente o resultado (elege-o, portanto, em objetivo final) ou apenas o tome como necessàriamente vinculado aos meios ou ao fim $\left({ }^{22}\right)$. Neste último aspecto a vontade não se dirige diretamente às circunstâncias típicas, mas toma-as como meios necessários ao alcance do obje-

(17) Conf. Welzel, ob. cit. pág. 63.

(18) Conf. Maurach, ob cit. pág. 314.

(19) Conf. Welzel, ob. cit. pág. 63; também Jescheck, ob. cit. pág. 199.

(20) Conf. Welzel, Ob. Cit. pág. 64; exigindo a probabilidade, Baumann - Strafrecht, A.T., 1965, pág. 376.

(21) Conf. Welzel, Ob. Cit. pág. 64.

(22) Conf. Mezger - Bei, Strafrecht, Studienbuch, 1965, pág. 173-Vol. 1. A.T. 
vo final ou como conseqüências ligadas necessàriamente ao emprego dos meios e ao alcance do fim. O que caracteriza esta situação é a representação da necessidade dos meios, entendida no sentido de êstes se constituirem em fatores causuais indispensáveis à obtenção do objetivo. ${ }^{23}$ ) Tomados os meios como fatores causais necessários, está claro que pode acontecer de o agenie nem desejar, primàrïamente, utilizá-los, porém, haverá, em qualquer caso, um liame subjetivo entre a representação - vontade e o fato, caracterizador do dolo direto. A êste respeito, bem esclarece Maurach, com base na jurisprudência do Reichsgericht, que o fato de o autor desejar um resultado extra-típico e reconhecer como necessário o resultado típico, estende a vontade da ação a este último, ainda quando seja tomado em consideração pelo sujeito de modo contrário à sua vontade, como algo inevitável $\left({ }^{24}\right)$. Exemplo de ligação volitiva entre o querer um resultado extra-típico e tomar como meio necessário o resultado típico, encontra-se no fato de o agente incendiar uma casa, que possui conjuntamente com outra pessoa, com o fim de indenização de seguro. Está claro que a destruição da casa é meio necessário para o alcance do fim (seguro), o fato de o agente lamentar, inclusive, a sua destruição não ilide, pois o dolo direto de dano.

À medida que se vai descendo na intensidade consciente da representação do autor, encontra-se traços de ligação entre o dolo direto e o dolo eventual. É o que se dá com a vontade em relação à circunstâncias típicas como conseqüências acompanhantes do fato. Estas são registradas pelo autor apenas secundàriamente em vista de sua vontade e na medida em que o autor as reconheça como parte integrante do complexo total de realização. $\left({ }^{25}\right)$ Estas circunstâncias ligam-se ao processo de representação do agente, apenas quando êste reconhece, que empregando os meios necessários ao alcance do objetivo, pode levá-las consigo, como efeitos paralelos ou independentes a êste objetivo. Trata-se de caso diverso da tomada das circunstâncias típicas como meios necessários ao alcance do fim. Naquele há predominância do elemento volitivo: $\bigcirc$ agente quer $\circ$ objetivo extra-típico diretamente e para isso deve eleger os meios para alcançá-lo. Êstes meios constituem fatores causais necessários ao alcance do fim e por isso deve o agente empregá-los, compreendendo-os indiretamente em sua vontade de realização. No caso em aprêço, há predominânciia do elemento intelectivo: o agente, ao empregar os meios, representativamente reconhece ou conta que as

(23) Conf. Welzel, Ob. Cit. Pág. 64.

(24) Conf. Maurach, Ob. Cit. Pág. 314 ss.

(25) Conf. Welzel, Ob. Cit. pág. 64. 
circunstâncias acompanhantes constitui-se parte integrante do emprego dos meios ou do alcance do fim. $\left({ }^{26}\right)$ A ligação necessária entre as consequiências e o emprêgo dos meios ou o alcance do fim é que possibilita estender-se a elas a vontade de realização do autor. Referentemente à ligação necessária das conseqüências ao emprêgo dos meios, deve ser considerada como certa pelo autor a verificação destas consequiências; no caso de ligação com o fim já basta a possibilidade de sua verificação, pois o alcance do fim pode ser tido sòmente como possível. $\left({ }^{27}\right)$

Como exemplo de ligação necessária entre as consequências acompanhantes e o emprêgo dos meios ou o alcance do fim, situa-se o caso referido por Binding a respeito de Alexander Keith (Thomas), que colocara uma máquina infernal a bordo de um navio para que êsie afundasse depois de oito dias, entre Southampton e Nova lorque, a fim de que êle recebesse o prêmio do seguro, apesar de contar como certa a morte das pessoas a bordo. Êste caso há, evidentemente, dolo direto em relação à morte das pessoas, embora êste não fôsse o objetivo do agente. $\left({ }^{28}\right)$

\section{DOLO EVENTUAL}

Agir com dolo eventual significa que "o autor toma a realização do tipo sèriamente como possível e com isto se conforma". $\left({ }^{29}\right)$

O autor neste caso representa as conseqüências como possíveis de serem derivadas do emprêgo de meios ou do alcance do objetivo e se conforma com a sua verificação. A diferenciação com o dolo direio deve se dar, primeiramente, em que naquele, a associação representativa se fixa na certeza de que as conseqüências ligar-se-ão necessàriamente aos meios ou ao fim, enquanto que neste esta ligação se representa apenas como possível na mente do autor. O caráter de ligação necessária ou sòmente possível na mente do autor é que marca já, dentro do momento intelectivo, a linha divisória entre as duas espécies de dolo. Porém ao representar como possível a verificação das conseqüências, pode $\circ$ auior peentrar em duas situações distintas:

a) - contar ou conformar-se com o acontecimento, ou

b) - confiar na sua não verificação.

(26) Conf. Welzel, ob. Cit:. pág. 64.

(27) Conf. Welzel, Ob. Cit. pág. 65.

(28) Conf. Binding, Normen, II, pág. 852; Veja-se a respeito, ainda, Baumann, Ob. Cit. pág. 377.

(29) Conf. Jescheck, Ob. Cit. Pág. 201. 
Na primeira (contar ou conformar-se com o acontecimento), a vontade de realização se caracteriza como dolo eventual. Na segunda, não há pròpriamente vontade de realização, sendo sòmente admitida a hipótese de culpa consciente. $\left({ }^{30}\right)$ Em forma concreta, segundo Welzel, devemos diferenciar nestas duas siíuações acima, dois grupos de casos, conforme o autor tenha a verificação das consequiências em dependência da sua atividade ou independentemente desta. $\left({ }^{31}\right)$ No primeiro caso, pode o autor não atribuir a si mesmo qualquer chance de evitar o resultado, cuja verificação deixa ao acaso. Aqui haverá dolo eventual, porque a dependência da atividade futura é menosprezada conscientemente pelo autor, o que demonstra indiretamente uma voníade de realização, um conformar-se com o resultado. Ainda neste caso pode o autor confiar em poder evitar $\circ$ resultado, através da condução de sua atividade, em razão de sua habilidade, presença de espírito, atenção ou cuidado. ${ }^{(32}$ Então atua - autor sem voníade de realização, mas apenas com culpa consciente. Assim, no famoso caso citado por Lacmann: A aposta com B de que acertará numa bola de vidro colocada na mão de u'a moça, encarregada de segurá-la, usando de um rifle e sem produzir lesões de qualquer espécie. Se produzir lesões, há que se distinguir o fato em relação às regras apresentadas: se o autor confiou, através de sua habilidade (por estar seguro de si mesmo), de que poderia evitar o resultado, haverá sòmente culpa consciente; se, contudo, o autor, consciente de sua inabilidade, conta com a possibilidade de verificação das lesões (ou conforma-se com esta possibilidade), haverá dolo eventual. ( $\left.{ }^{33}\right)$.

No segundo grupo de casos, referido por Welzel, (o auior tem a verificação das conseqüências independentemente de sua atividade), o autor pode estar em dúvida quanto a constituição do objeto do fato, como pode estar consciente de não poder evitar as conseqüências futuras, através da condução adequada de sua atividade. Haverá dolo eventual se o autor contar com a verificação das circunstâncias (consequiências) e culpa conscienie se possui apenas dúvida remota em relação a estas. ${ }^{(34)}$ Referentemente a êstes dois casos, situam-se como exemplos os fatos citados por Mezger: o autor quer subirair uma coisa, mas possui dúvida acêrca de se lhe pertence ou não (se é, enfim, coisa alheia). Se êle conta com a possibilidade

(30) Conf. Welzel, Ob. Cit. pág. 65.

(31) Conf. Welzel, Ob. Cit. pág. 65.

(32) Conf. Welzel, Ob. Cit. Pág. 65; veja-se, principalmente, Maurach, Ob. Cit. Pág. 221, 221, Vol. 2, sôbre conceito preciso de culpa consciente.

(33) Conf. Maurach, Ob. Cit. Pág. 318 - Vol. 1.

(34) Conf. Welzel, Ob. Cit. Pág. 66. 
de a coisa não lhe pertencer, haverá dolo eventual se possui, entretanto, apenas dúvida remota, haverá culpa consciente. Um rico proprietário rural mata com um disparo de fuzil um corvo situado além dos limites de sua propriedade, reconhecendo como possível esta situação no momento de disparar; haverá dolo eventual se êle contou com esta possibilidade; culpa consciente se possuia dúvida remota em relação a ela ${ }^{(35}$ ). Para esclarecer melhor a diferença ou os limites entre dúvida remota e 'contar com as consequências', pode-se tomar por base o critério de Mezger, alicerçado na probabilidade do acontecimento: se o autor pensa-o ou toma-o como possível, haverá dúvida remota e, conseqüentemente, culpa consciente se, pelo contrário, toma-o como provável, conta com o resultado, havendo dolo eventual. $\left.{ }^{(36}\right)$

Uma das questões mais difíceis do Direito Penal apàrece, justamente, na diferenciação entre dolo eventual e culpa consciente, chegando mesmo Roxin, um dos maiores penalistas alemães a afirmar que uma fixação conceitual neste terreno torna-se pouco possível de ser atendida. ${ }^{37}$ )

A teniativa de diferenciação teve lugar, primeiramente, através da elaboração de duas teorias que focalizavam o dolo, respectivamente, segundo o seu elemento intelectivo (teoria da probabilidade) ou volitivo (teoria do consentimento).

De acôrdo com a primeira busca-se encontrar uma diferença relevante na consciência do fato, por parte do autor, capaz de estabelecer as fronteiras dolosas e culposas ${ }^{(38)}$. Assim, agiria com dolo eventual o autor que tomasse o fato como provável e não sòmente como possível. Como bem salienta Schmidhäuser, esta teoria contraria os outros momentos do conceito corrente de dolo, pois pode existir também êste, quando o autor persegue um fim, cuja consecução é muito improvável (exemplo do tiro à distância, com dolo direto). $\left.{ }^{(39}\right)$ Porém pode-se valer desta teoria, como o faz Mazger, quando o acontecimenio independe da condução da atividade futura do agente. Nos moldes da segunda teoria, haverá dolo eventual, quanto o agente, além de tomar o fato como possível, consente no resultado. Não se exige que o agente tome o fato como provável, bastando a possibilidade de conexão entre as conseqüências e o emprêgo dos meios ou o alcance do fim. Esta teoria apresenta algumas variações,

(35) Conf. Mezger, Tratado de Derecho Penal (tradução espanhola), 1949, vol. 2, pág. 163/165.

(36) Conf. Mezger, Tratado, Vol. II, Pág. 163.

(37) Conf. Roxin, Juristische Schulung, 1964, Pág. 59.

(38) Conf. Jescheck, Ob. Cit. Pág. 203.

(39) Conf. Schmidhäuser, Strafrecht, A. T., 1970, n.० 10/94 ss. 
segundo se exija que o autor "iolere o resultado", "esłeja de acôrdo com êle" ou "assuma o risco de produzí-lo". Os Códigos Brasileiros de 1940 e de 1969 adotaram esta última variante, que vinha consignada no projeto alemão da época do nazismo $\left({ }^{40}\right)$ e que, com variações, teve acolhida no Projeto de Alternativas (A. E.) para a reforma penal naquele país (1966). Esta última regra acarretou sérias divergências entre os autores $\left({ }^{41}\right)$, que a abandonaram na recente lei alemã de reforma de 1969, por não esclarecer suficientemente o assunto. É evidente que a simples menção de "assumir o risco" não determina as fronteiras entre o dolo eventual e a culpa consciente. O projeto alemã de 1962, disciplinando a matéria, estabelece duas regras alternativas, de culpa consciente e dolo eventual, através das expressões "conformar-se com a possibilidade subsistente de realização do tipo" ou "confiar na sua não verificação", que devem ser entendidas como conceitos complementares, istio é, quem conforma-se com a possibilidade de realização do tipo não confia na sua não verificação e vice-versa, mas sòmente se conforma com a possibilidade de realização do tipo quem não confia na sua não verificação. ${ }^{\left({ }^{42}\right)}$ O Código Brasileiro de 1969 dispõe, mais ou menos nos mesmos moldes, com uma regra alternativa, ao definir o dolo eventual como assunção do risco do resultado e culpa consciente como previsão do resultado, em que o agente supõe levianamente que não se realizaria ou que poderia evitá-lo.

Seguindo a teoria do consentimento pode-se determinar o dolo eventual segundo duas conhecidas fórmulas de Frank. $\left({ }^{43}\right.$ ) A primeira, hoje quase que abandonada, esiabelece que só se alcança o conceito de dolo eventual, quando, além da previsão do resultado como possível, esta previsão de tal resultado como certo não houvesse se contraposto ao autor como um contra-motivo decisivo (teoria hipotética do consentimento). A segunda fórmula, que pode esclarecer acêrca do Código Brasileiro, indica que se o autor diz a si mesmo: "seja assim ou de outra forma, suceda isto ou aquilo, em qualquer forma atuo" haverá dolo eventual (teoria positiva do consentimento). Haveria, assim, culpa consciente, quando o autor, se soubesse que o resultado se produziria com certeza, não teria atuado. O que marca o dolo eventual para esta teoria é a posição do autor em relação à preferência da execução da ação perigosa, apesar de concorrer a possibilidade de produção do resultado. Contra a posição mantida

(40) Conf. Nelson Hungria, Comentários, 1958, Vol. I, tomo II, Pág. 121.

(41) Conf. Crítica de Jescheck, Obra Cit. Pág. 201.

(42) Conf. Jescheck, Ob. Cit. Pág. 202.

(43) Conf. Mezger, Tratado, Pág. 160, Vol. II. 
por essa teoria é de se salientar, principalmente, a sua rigidez excessiva. Como bem esclarece Welzel, seguida por Jescheck e por Maurach, essa teoria desconhece, justamente, que a vontade de realização (dolo) pode f'ambém relacionar-se com alguns resultados que o autor em nenhuma hipótese consente, mas até repele ou lamenta

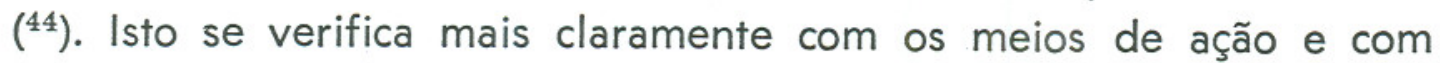
as conseqüências acompanhantes previstas como possível, com as quais conta $\circ$ autor. $O$ famoso caso decidido pelo Supremo Tribunal alemão sob n. 7.363 seria enquadrado, no Direito Brasileiro, como culpa consciente: dois ladrões pretendem roubar $X$ depois de o haverem reduzido à incapacidade de resistência. Como meio para romperem a resistência de $X$, escolhem, primeiramente, uma correia que deveria ser colocada no pescoço da vítima. Como, entretanio, contassem com a possibilidade da morte de $\mathrm{X}$, por estrangulamento, decidem abandonar êste meio e utilizar um pequeno saco de areia, com o qual $X$ deveria ser atordoado. Assim, conduzem, primeiramente, sua atividade. Seu objetivo é a bolsa da vítima, como a evitabilidade de sua morte. Quando, porém, o saco de areia não atordoa a vítima, os autores se voltam para o primeiro meio, afixando-o na garganta da vítima e deixando-o prêso a uma fivela, enquanto roubam e empacotam suas coisas. Quando, porém, soltam a correia $X$ encontrava-se morto. Segundo a regra do direito brasileiro, de analisar exclusivamente, o fato de modo isolado, haveria tão só culpa consciente, pois os autores não assumiram o risco da morte de $X$, pois até a excluiram de seus planos, supondo que ela não ocorresse. Porém, como contaram anteriormente com a possibilidade da produção dessa morte, é certo que isto se liga à vontade de realização (dolo), pois ao mudarem de meio para alcançar o objetivo visado, tiveram como possível a produção das conseqüências conforme seu plano anterior, conformando-se com isto.

A melhor solução será dada, assim, dentro do caso concreto, devendo observar-se o complexo total de realização e não, simplesmente, o resultado típico de forma isolada, com base em regras rígidas. $\left.{ }^{(45}\right)$

(44) Conf. Welzel, Ob. Cit. Pág. 66; Jescheck, Ob. Cit. Pág. 203.

(45) Conf. Maurach, Ob. Cit. Pág. 318; Também Mezger, Tratado, Pág. 161, Vol. II; entre nós observa Anibal Bruno, "Direito Penal", Vol. II, 1959, Pág. 76, que se, da observação das circunstâncias do fato concreto, não se conduz seguramente a uma conclusão, e a dúvida se mantém a respeito da configuração do dolo eventual ou da culpa consciente, deve-se admitir a solução menos severa, que é a da culpa consciente (neste mesmo sentido veja-se Von Hippel, Deutsches Strafrecht, 1925-1930, Vol. II, Pág. 315). 


\section{ESPÉCIES DE DOLO NOS TIPOS PENAIS}

O Código Penal Brasileiro equiparou, para efeito de igual tratamento, as duas espécies de dolo: dolo direto e dolo eventual. Há ocasiões, entretanto, que a lei exige um conhecimento mais certo por parte do autor das circunstâncias típicas, descartando, destarte, o dolo eventual e acolhendo, ùnicamente, o dolo direío. Tal ocorre, principalmente, quando o texto legal se refere a certas expressões como "com consciência", "conscientemente" ou "de que sabe", etc.

Além disso, embora o dolo eventual se equipare ao dolo direto, deve-se atender a diferenciação para a medida da pena, conforme, aliás, exigência do Art. 22 do estatuto vigente e Art. 52 do Código de 1969. A expressão ali contida acêrca de "intensidade do dolo" só pode ser entendida em relação ao dolo direto e ao dolo eventual.

\section{ELEMENTOS SUBJETIVOS DO TIPO}

Ao lado do dolo, podem figurar nos tipos penais, outras séries de características psíquicas ou determinadas psiquicamente, que servem à estrutura ou fundamentam certos tipos agravados ou atenuados.

Estas figuras, que correspondem a uma tendência subjetivadora do legislador, vêm originar uma nova modalidade de sistemaitização do delito. Geralmente os autores as enquadram no setor da antijuridicidade, sob a denominação de "elementos subjetivos do injusto" $\left.{ }^{46}\right)$, por considerá-las como pertencentes à caracterização do injusto de uma espécie de delito. Hoje são êstes elementos estudados dentro do tipo, por razões sistemáricas e porque formam, de qualquer modo, a estrutura do tipo. ${ }^{\left({ }^{47}\right)}$ Contudo, as expressões "elementos subjetivos do tipo" e "elementos subjetivos do injusto" possuem - mesmo significado. Também deve ser salientado, como bem observa Jescheck, que nem todos os fatores psíquicos descritos como parte integrante de uma disposição penal consíituem elementos subjetivos do tipo. Paralelamente a êstes há, ainda, os elementos da culpabilidade, que, às vêzes, na prática, podem ser confundidos com aquêles. A diferença entre êles se apresenta como quesião árdua do Direito Penal e deve partir do conceito que se tenha do injusto e da culpabilidade. Segundo Schweikert ${ }^{48}$ ), caracterizam a culpabilidade aquêles elementos que afetam a existência ou o grau de reprovabi-

(46) Veja-se, por exemplo, Mezger, Tratado, Pág. 333, Vol. I; no Brasil, segue a mesma orientação Anibal Bruno, Ob. Cit. Vol. I, Pág. 346.

(47) Conf. Jeschek, Ob. Cit., Pág. 213.

(48) Conf. Schweikert, Die Wandlungen der Tatbestandslehre seit Beling, 1957, Pág. 148. 
lidade, enquanto pertencem ao tipo os elementos ligados ao ânimo do autor. Mais claramente, pode-se reconhecer que para 0 injusto do fato, êstes caracteres subjetivos serão sòmente determinantes quando caracterizam a vontade de agir do autor ou indicam a forma de comissão do fato ou o bem jurídico protegido, enquanto os elementos da culpabilidade serão aquêles que atingem mais profundamente a vontade do auíor em relação aos seus motivos, indicativos de maior ou menor reprovabilidade. $\left({ }^{49}\right)$ A diferenciação tem grande importância no tratamento penal do inimputável. Se, por outro lado, é pacífica a admissão da vontade no inimputável, por outro seria, as vêzes, de todo impróprio atribuir-lhe certas qualidades, que só dizem respeito à reprovabilidade do fato, como a boa ou má fé, a torpeza e outros motivos. Os elementos subjerivos do tipo, dizendo respeito à vontade do autor, dirigida a um fim determinado, previsto pelo tipo, englobam assim o antigo dolo específico.

Também é de se notar a diferença entre os genuínos elementos subjetivos do tipo e formas qualificadas de dolo. Por estas últimas entende-se uma série de delitos, nos quais o dolo deve ter em vista deierminados fins, que não chegam a ultrapassá-lo, mas que se encontram dentro da área de sua extensão e devem ser por êle englobados. $\left({ }^{50}\right)$ Tal se verifica nos delitos em que o agente pratica duas ações materiais (uma serve de meio à outra) ou em que o agente pratica uma ação no sentido de que outra pessoa faça algo que aquêle tem em vista. $\left({ }^{51}\right)$ No Direito Brasileiro encontram-se entre outros exemplos de dolo qualificado justamente nos crimes de denunciação caluniosa e consirrangimento ilegal.

Pràticamente, costumam-se classificar os elementos subjetivos do tipo em dois grupos: $\left({ }^{52}\right)$

1. O primeiro compreende os chamados delitos de intenção, em que se exige do agente a persecução de um objetivo compreendido no tipo, isto é, referido no tipo, mas que êle não precisa alcançar pràticamente. $O$ crime se consuma, desde logo, com a ação do agente. Aqui se situam os delitos que contenham expressões designativas de inienções especiais, como "para...", com o fim de...", "para fim de...", "em proveito...", etc.

(49) Conf. Jescheck, Ob. Cit. Pág. 214.

(50) Conf. Maurach, Ob. Cit. Pág. 328.

(51) Veja-se análise de Welzel a respeito, sob outro prisma, Ob. Cit. Pág. 76.

(52) Mezger e Jescheck compreendem, ainda, os delitos de expressão, entre os grupos de elementos subjetivos do tipo. Esta colocação, entretanto, se nos parece difícil de ser atendida face às normas do Direito Brasileiro. Veja-se à respeito, Mezger, Tratado, Vol. 1, Pág. 345 e Jescheck, Ob. Cit. Pág. 215. 
2. O segundo grupo corresponde aos delitos de tendência, nos quais a ação do fato torna-se dominada através de uma direção de vontade do autor, que não possui correspondência integral no acontecimento objetivo. $\left({ }^{53}\right)$ A êsie grupo, entre outros, pertencem os delitos contra os cosiumes que, segundo sua natureza, exigem que a ação se desenvolva seguindo uma intenção sexual. $\left({ }^{54}\right)$

O conhecimento dêstes elementos subjetivos do tipo se apresenta de particular importância prática no concurso de agentes e na tentativa.

No caso de co-autoria devem ser atendidos por todos os coautores. Para os pariícipes ou instigadores basta que sejam atendidos pelo autor principalmente e que os mesmos tenham consciência dis†o. $\left({ }^{55}\right)$

Na tentativa devem estar presentes em tôda a sua extensão, pois o que falta neste caso é simplesmente a consumação do tipo objetivo. $\left({ }^{56}\right)$

Sendo, finalmente, tais elementos, assim como o dolo, parie do tipo, devem estar presentes quando se queira aplicar a um inimputável uma medida de segurança, pois sua ausência acarretaria desnaturação da figura típica e conseqüentemente do pressuposto da medida. $\left({ }^{57}\right)$

(53) Conf. Jescheck, Ob. Cit., Pág. 215.

(54) Conf. Jescheck, Ob. Cit. Pág. 215; Veja-se ainda Heleno Fragoso, lições, Vol. 2, Págs. 495 ss., 1962, que admite o dolo específico nos crimes contra a liberdade sexual.

(55) Conf. Jescheck, Ob. Cit. Pág. 215.

(56) Conf. Jescheck, Ob. Cit. Pág. 215/216.

(57) Conf. Jescheck, Ob. Cit. Pág. 215. 